\title{
Role of Antidiuretic Hormone in the Abnormal Water Diuresis of Anterior Hypopituitarism in Man
}

\author{
Zalman S. Agus and Martin Goldberg \\ From the Renal-Electrolyte Section, Department of Medicine, University of \\ Pennsylvania School of Medicine, Philadelphia, Pennsylvania 19104
}

\begin{abstract}
A B S T R A C T To evaluate the role of antidiuretic hormone $(\mathrm{ADH})$ in the defect in water excretion which is characteristic of glucocorticoid deficiency, the effects of hydrocortisone and ethanol upon urinary dilution during a sustained water load were studied in patients with anterior hypopituitarism. A spectrum of defects in urinary dilution was found in the seven patients with anterior hypopituitarism, and the subjects were separable into two groups. Four patients were unable to excrete a urine hypotonic to plasma (group I) while three diluted the urine (group II). In two of the group II patients, despite maintenance of hydration, urinary osmolality later rose to hypertonicity. Physiological doses of hydrocortisone improved urinary dilution in all patients. Submaximal doses of oral hydrocortisone, when given to the group I patients, converted their response to hydration to one characteristic of the group II patients, i.e., an initial hypotonic urine followed by a secondary rise to hypertonicity. Ethanol, a known inhibitor of ADH secretion, had no effect in the group I patients. When two of these patients were pretreated with submaximal doses of hydrocortisone, however, so that they were able to transiently dilute the urine, ethanol prevented the secondary rise in urine osmolality. Similarly, the administration of ethanol to the untreated group II patients, when the urine was hypotonic, improved diluting ability as characterized by a lowering of urinary osmolality and an increased excretion of solute-free water in all three patients. Hydrocortisone did not improve urinary dilution in three patients with complete hypophyseal diabetes insipidus and one with both anterior and posterior insufficiency receiving constant infusions of vasopressin. These data suggest, therefore, that inappropriately elevated levels of $\mathrm{ADH}$ play a major role in the defect in water excretion of anterior hypopituitar-
\end{abstract}

\footnotetext{
A preliminary report of this work was published: 1962. Trans. Ass. Amer. Physicians Philadelphia. 75: 129.

Received for publication 7 December 1970 and in revised form 16 February 1971.
}

ism. Glucocorticoids appear to be necessary for a normal neurohypophyseal response to inhibitory stimuli.

\section{INTRODUCTION}

A defect in the excretion of a water load and its correction by glucocorticoid administration have been well documented in patients with hypopituitarism and adrenal insufficiency (1-5), but the physiologic mechanisms underlying these observations have not been completely elucidated. While several mechanisms may contribute to the defect in water excretion in hypopituitarism, many feel that the major factor is insufficient impermeability to water of the distal tubular and collecting duct epithelium due either to a direct effect of glucocorticoid deficiency or indirectly via elevated levels of circulating antidiuretic hormone $(\mathrm{ADH})$. The role of elevated levels of $\mathrm{ADH}$, first suggested in 1949 (6) and supported by the observations of Dingman and Despointes (5), has not as yet been definitively established. Bioassays have shown both sustained high $\mathrm{ADH}$ levels (7) and undetectable $\mathrm{ADH}$ blood levels (8) in patients with glucocorticoid deficiency. Furthermore, the difficulty inherent in interpreting data derived from bioassay studies of this problem is evident by the fact that neither of these observations has been confirmed by other investigators; also the results of one of these studies (8) could not be reproduced by the senior investigator working in another laboratory (9).

The present study was undertaken in order to characterize further the defect in water excretion and to evaluate the role of elevated levels of ADH in patients with hypopituitarism. Patients with anterior and posterior hypopituitarism were studied during a sustained water load using standard clearance techniques, and the effects of hydrocortisone and ethanol, a known inhibitor of ADH secretion (10-12), upon urinary dilution were evaluated. All patients with anterior hypopituitarism demonstrated an abnormality in the ability to dilute the 
urine, but a wide spectrum of defects was found. Both hydrocortisone and ethanol administration effected improvement in urinary dilution in these patients while hydrocortisone did not influence urinary dilution in patients with posterior pituitary insufficiency receiving infusions of vasopressin. The data suggest a major role for inappropriately elevated levels of $\mathrm{ADH}$ in the defect in water excretion of glucocorticoid-deficient man.

\section{METHODS}

\section{Subjects}

29 studies were performed on seven patients with anterior hypopituitarism, three patients with complete central dia- betes insipidus off vasopressin therapy, and one with both anterior and posterior pituitary insufficiency. The diagnosis of hypopituitarism was established by determinations of urinary gonadotrophins, 17-ketosteroids, 17-hydroxy steroids, response to $\mathrm{ACTH}$ and metyrapone, $\mathrm{PBI},{ }^{181} \mathrm{I}$ uptake, and response to thyroid-stimulating hormone. Patients were selected for study on the basis of availability before initiation of therapy and not because of the presence of hyponatremia. Posterior pituitary insufficiency was diagnosed by hypertonic saline infusion, water deprivation (urine osmolality less than $100 \mathrm{mOsm} / \mathrm{kg}$ ), and response to intravenous vasopressin (urine osmolality greater than $500 \mathrm{mOsm} / \mathrm{kg}$ ). All patients were admitted to the Clinical Research Center of the Hospital of the University of Pennsylvania and placed on a constant sodium and potassium intake of approxi-

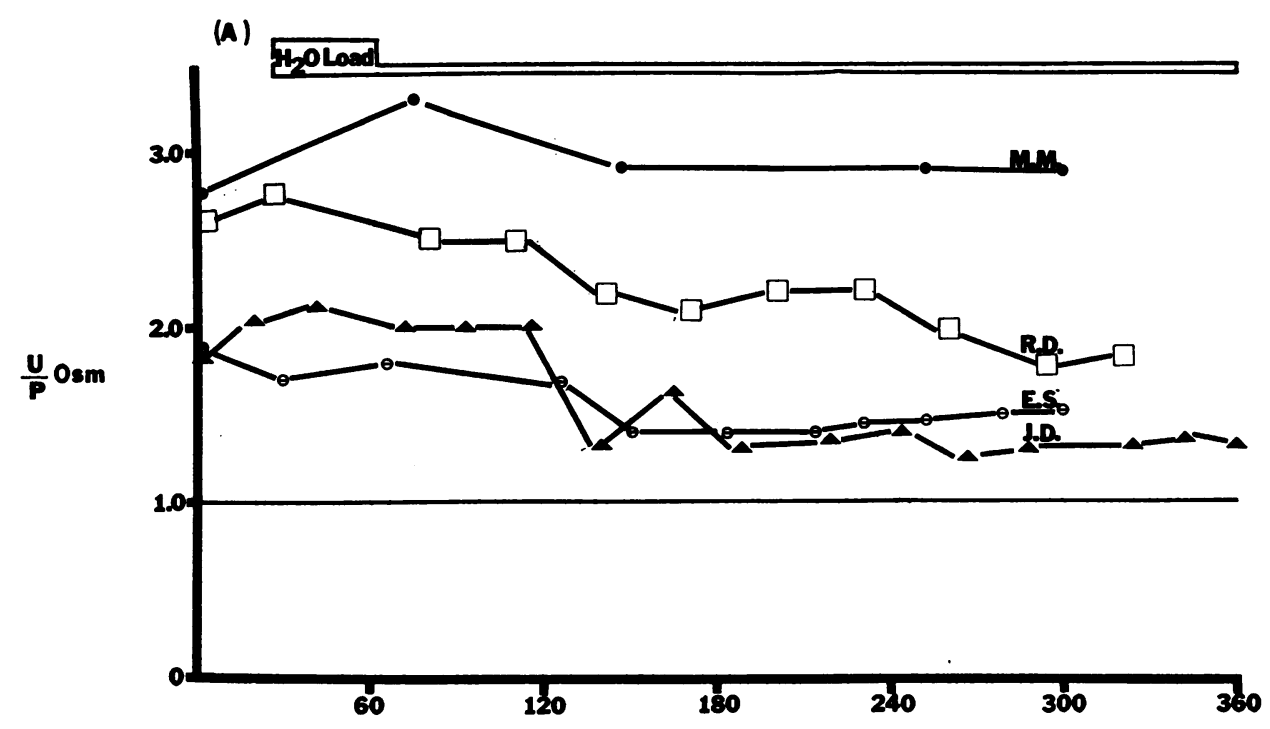

(B)

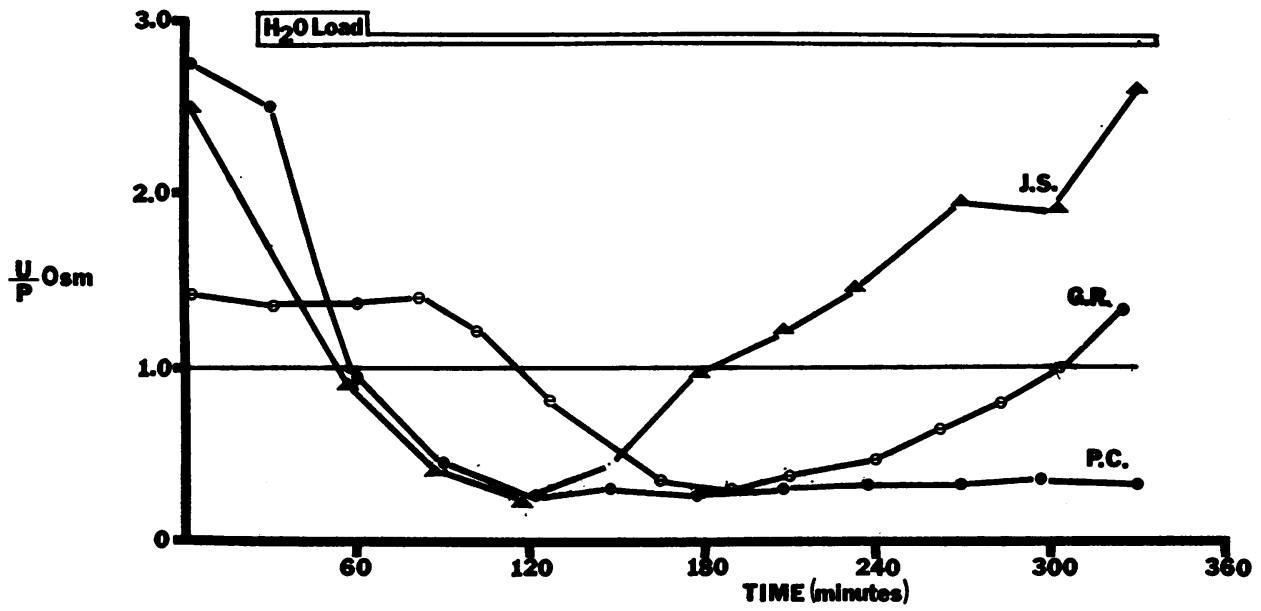

FIGURE 1 Response to a sustained water load in seven patients with anterior hypopituitarism, four of whom were unable to excrete a hypotonic urine (A) and three of whom were able to excrete a hypotonic urine (B). In two of the patients in the latter group, urinary hypotonicity could not be sustained despite maintenance of the water load. 
(A)

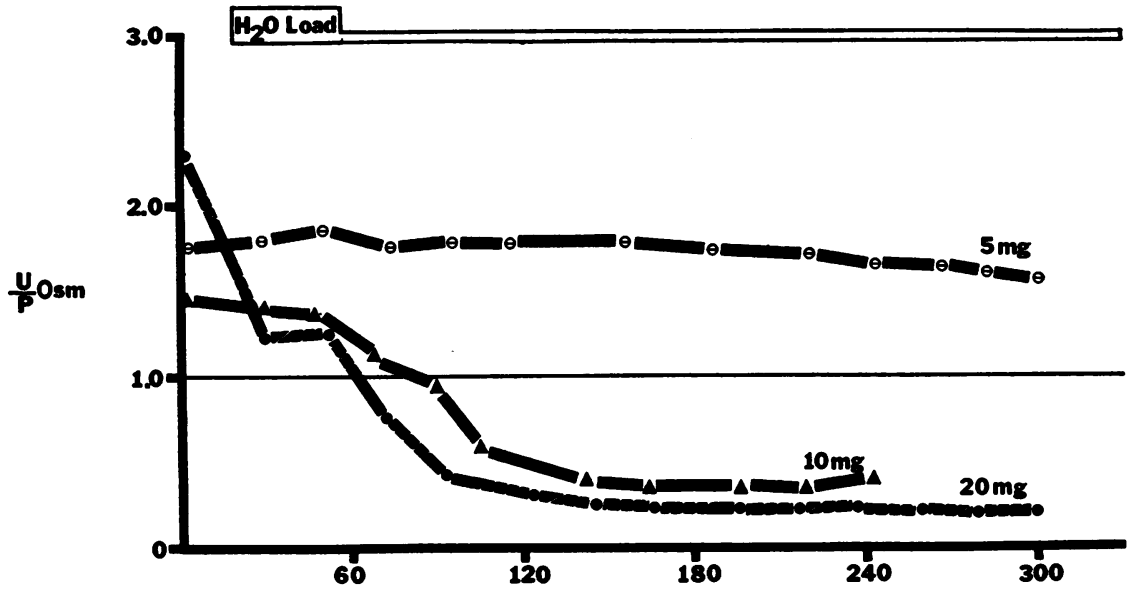

(B)

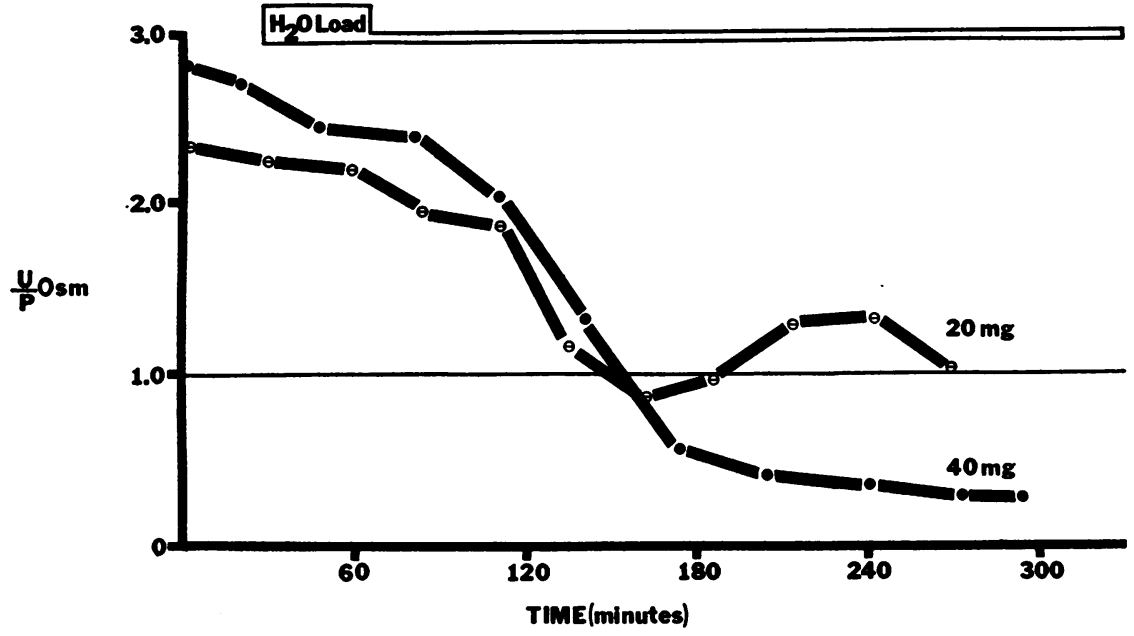

FIGURE 2 The effect of the administration of graded doses of oral hydrocortisone $1 \mathrm{hr}$ before the initiation of a sustained water load in patients E. S. (A) and R. D. (B).

mately 100 and $40 \mathrm{mEq}$, respectively, for several days before performance of the studies.

\section{Protocols}

\section{ANTERIOR Hypopituitarism}

Sustained water load. After 8-10 $\mathrm{hr}$ of hydropenia, 20 $\mathrm{ml} / \mathrm{kg}$ of fluids was administered over $30-45 \mathrm{~min}$ either as tap water by mouth or as intravenous $4 \%$ fructose in water at 8-10 a.m.; during the entire experiment, the patient remained in the recumbent position. Subsequent fluids were administered in amounts equal to urine flow plus estimated insensible loss $(40-50 \mathrm{ml} / \mathrm{hr})$. Urine samples were collected every $30-60 \mathrm{~min}$ in most subjects by having the patient stand to void. In three patients, indwelling urinary catheters were necessary to facilitate accurate collections. Informed consent was obtained, and urine cultures $48 \mathrm{hr}$ and 7 days after the studies revealed no growth. In order to minimize the influence of noxious stimuli on the water diuresis, venipunctures were not performed during the development or peak of a water diuresis, but only $1 \mathrm{hr}$ before the water load was begun, at the end of the study, or after a definite decrease in free water clearance or rise in urinary osmolality.

Hydrocortisone. In two patients, $100 \mathrm{mg}$ of hydrocortisone was given intravenously during a sustained water load at a time when the urine was hypertonic to plasma. In five patients, hydrocortisone was given orally in doses of $5,10,20$, or $40 \mathrm{mg}, 1 \mathrm{hr}$ before initiation of a sustained water load. Fluid replacement, blood, and urine collections were obtained as above.

Ethanol. Ethyl alcohol was administered as 100 proof whiskey diluted with small amounts of juice or carbonated beverage to five patients at varying times during a sustained water load as described above. 
Ethanol plus hydrocortisone. In two patients, who failed to respond to alcohol alone, identical studies were performed after pretreatment with hydrocortisone in doses of 10 and $20 \mathrm{mg}$. Ethyl alcohol was administered as previously during a sustained water load, and blood and urine collections were obtained as above.

\section{Posterior Pituitary Insufficiency}

Three patients with complete central diabetes insipidus and one with anterior and posterior pituitary insufficiency received a sustained water load. Fluid maintenance, blood, and urine collections were performed as above. Simultaneously with the water load, constant infusions of aqueous vasopressin providing $8-15 \mathrm{mU} / \mathrm{hr}$ were administered with a Harvard constant infusion pump. $100 \mathrm{mg}$ of hydrocortisone was given intravenously during the study after a stable antidiuresis had been obtained.

\section{Methods}

Urine and serum electrolytes were determined by flame photometry and creatinine as previously described (13). Osmolalities were determined with a Fiske osmometer and corrected for ethanol concentration. Ethanol concentrations of blood and urine were estimated by the microdiffusion method of Conway and Nolan, modified after Winnick (14). Solutions of known concentration of ethanol in serum were checked both by chemical analysis and osmometry. Endogenous creatinine clearance was determined in the usual manner. Osmolar clearance $\left(\mathrm{C}_{0 s m}\right)$ and free water clearance $\left(\mathrm{C}_{\mathrm{H}_{2} \mathrm{O}}\right)$ were calculated by the following formulas:

$$
\begin{gathered}
\mathrm{Cosm}_{\mathrm{m}}=\mathrm{U}_{\mathrm{os} \mathrm{m}} / \mathrm{Posm}_{\mathrm{m}} \times \mathrm{V} \\
\text { and } \mathrm{C}_{\mathrm{H}_{2} \mathrm{O}}=\mathrm{V}-\mathrm{C}_{\mathrm{Os} \mathrm{m}}
\end{gathered}
$$

where $P_{0 s m}=$ osmolality of the serum (milliosmols per kilogram) and $\mathrm{V}=$ urine flow (milliliters per minute).

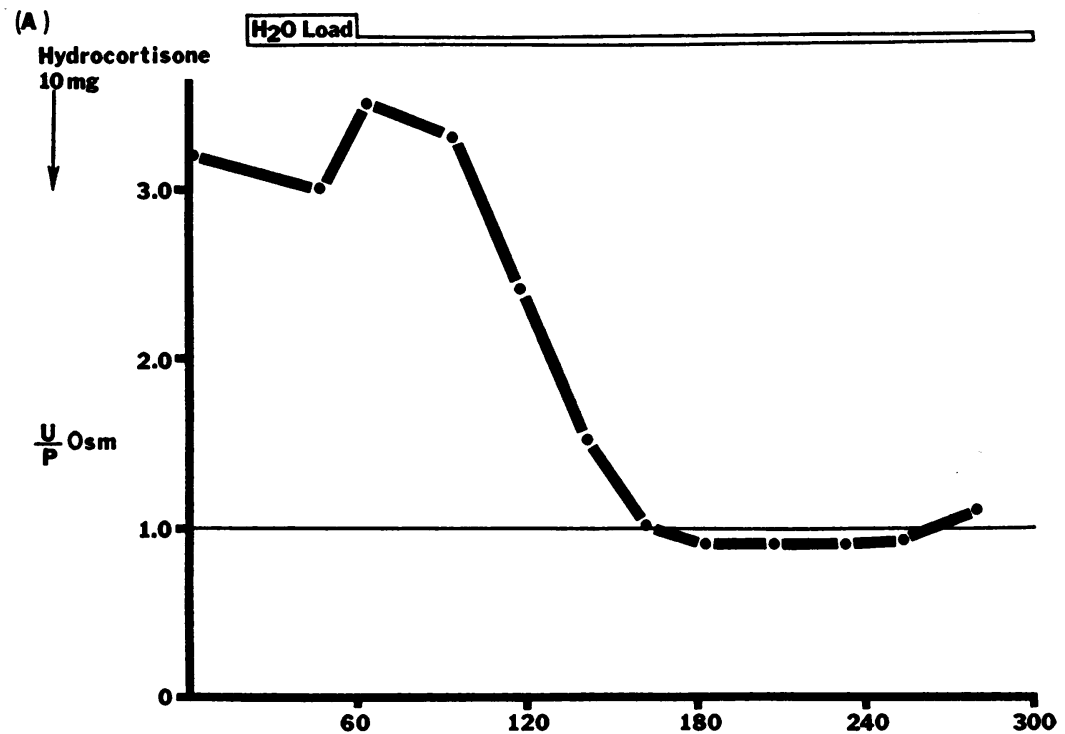

(B)

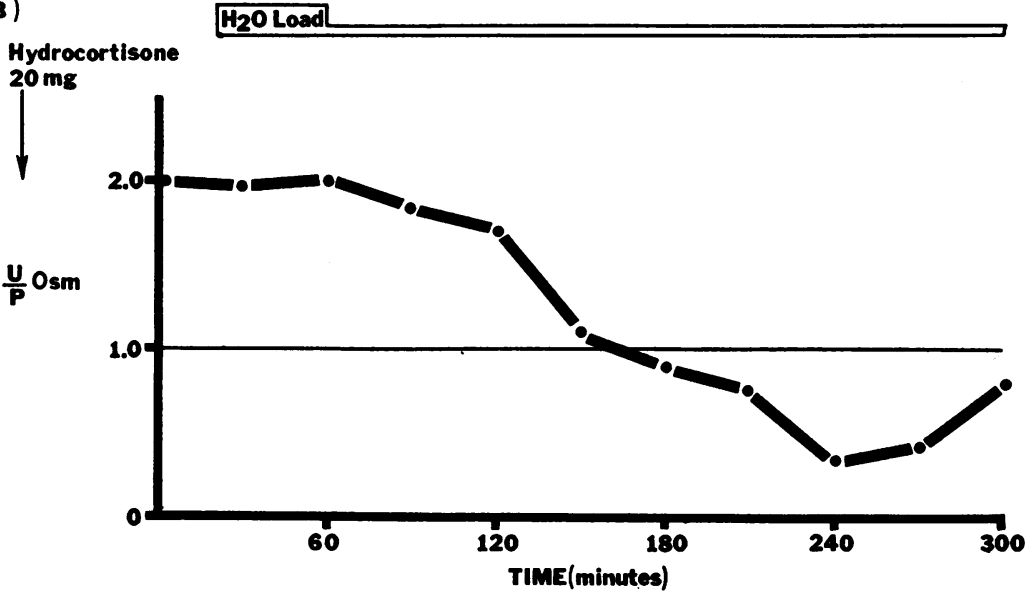

FIgURE 3 The effect of the administration of oral hydrocortisone $1 \mathrm{hr}$ before the initiation of a sustained water load in patients M. M. (A) and J. D. (B). 


\section{RESULTS}

\section{Anterior hypopituitarism}

Response to sustained water load. The normal response to a sustained water load of comparable duration has been previously published (15) and is characterized by maintenance of urine hypotonicity and a urine/ plasma (U/P) osmolal ratio of less than 0.3 throughout the study. In all seven patients in the present study, there was a defect in water excretion manifested by an inability to dilute maximally the urine in response to a standard water load. The response, however, was variable, and the patients could be divided into two groups. Group I, as shown in Fig. 1(A), included four patients who were unable to excrete a dilute urine and maintained a U/P osmolal ratio of greater than 1 throughout the study. Three of the four patients (J. D., E. S., and M. M.) manifested hyponatremia, ranging from 120 to $130 \mathrm{mEq} / 1$ before the institution of the studies. Group II, as shown in Fig. 1(B), consisted of three patients who were able to excrete a urine hypotonic to plasma. In two, J. S. and G. R., this was not sustained, and the $U / P$ ratio gradually rose to hypertonic levels despite maintenance of the water load. The third patient, P. C., had a very mild defect recognizable only when compared with the studies obtained after hydrocortisone and alcohol as will be shown below. None of the group II patients mainfested hyponatremia during their course.

Response to hydrocortisone. The administration of hydrocortisone in all patients produced a rapid improvement in the ability to excrete a water load. The effects of hydrocortisone given orally $1 \mathrm{hr}$ before the institution of the water load in the group I patients are shown in Figs. 2 and 3. The response to glucocorticoid administration appeared to be dose related. Thus, in E. S., as shown in Fig. 2A, the oral administration of 5,10 , and $20 \mathrm{mg}$
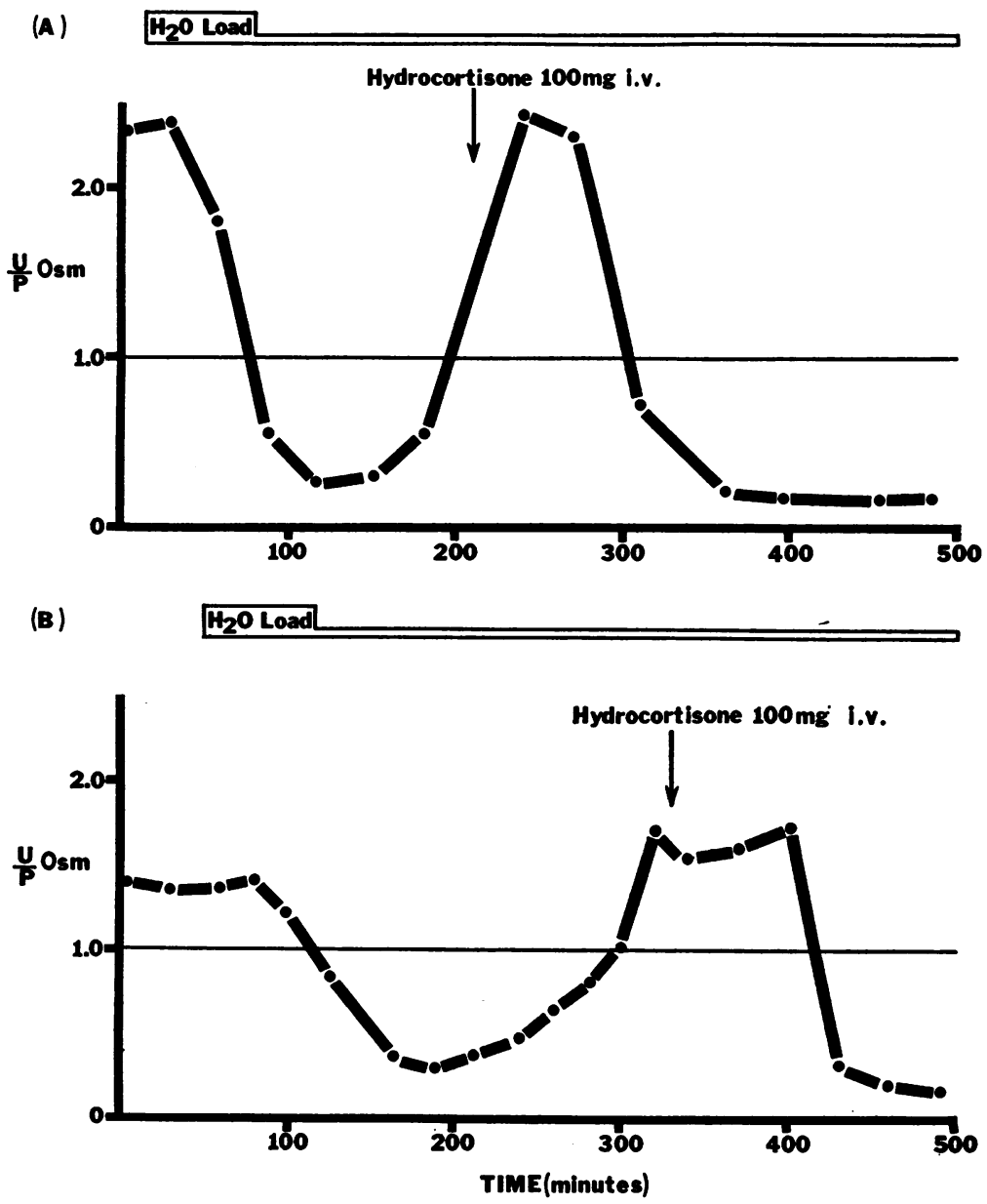

FIGURE 4 The effect of intravenous hydrocortisone given at a time when the urine was hypertonic upon urinary dilution in patients $J$. S. (A) and G. R. (B) during a sustained water load. 
TABLE I

Response to Hydrocortisone

\begin{tabular}{|c|c|c|c|c|c|c|c|c|c|}
\hline \multirow[b]{2}{*}{ Patient } & \multicolumn{4}{|c|}{ Before therapy* } & \multirow[b]{2}{*}{ Dose } & \multicolumn{4}{|c|}{ After hydrocortisone* } \\
\hline & $\mathrm{C}_{\mathrm{Cr}}$ & Min. Uosm & $\mathrm{C}_{\mathrm{H}_{2} \mathrm{O}}$ & Cosm & & $\mathrm{C}_{\mathrm{Cr}}$ & Min. Uosm & $\mathrm{C}_{2} \mathrm{O}$ & Cosm \\
\hline & $m l / m i n$ & $m O s m / k g$ & $m l / m i n$ & $m l / m i n$ & $m g$ & $m l / m i n$ & $\mathrm{mOsm} / \mathrm{kg}$ & $m l / \min$ & $m l / \min$ \\
\hline M. M. & 74 & 709 & -0.8 & 1.71 & 10 & 74 & 213 & 0.5 & 3.6 \\
\hline R. D. & 125 & 494 & -0.8 & 1.7 & 40 & 115 & 66 & 8.0 & 2.5 \\
\hline E. S. & 48 & 391 & -0.35 & 1.03 & 20 & 69 & 50 & 9.2 & 2.31 \\
\hline J. D. & 60 & 330 & -1.0 & 4.0 & 20 & & 83 & & \\
\hline J. S. & 106 & 83 & 3.5 & 1.4 & 100 & 118 & 51 & 7.4 & 1.6 \\
\hline G. R. & 57 & 90 & 2.9 & 1.5 & 100 & 65 & 42 & 6.1 & 1.5 \\
\hline P. C. & 95 & 75 & 4.1 & 1.6 & 20 & 66 & 61 & 8.3 & 2.3 \\
\hline
\end{tabular}

$\mathrm{C}_{\mathrm{Cr}}, \mathrm{C}_{\mathrm{H}_{2} \mathrm{O}}$, and $\mathrm{C}_{\mathrm{Osm}}=$ clearance of creatinine, solute-free water, and osmols, respectively. Min. $\mathrm{U}_{\mathrm{Osm}}$ $=$ minimal urinary osmolality.

* Values represent the mean of two to three consecutive periods at a time of minimal urinary osmolality during a standard water load. In five patients, the values were obtained in two separate studies. The control values were obtained during a standard water load and the hydrocortisone values during a study preceded by an oral dose of hydrocortisone. In two patients, J. S. and G. R., hydrocortisone was given intravenously during the study, and the values given represent the mean of two to three consecutive periods at a time of minimal urinary osmolality before and after hydrocortisone infusion.

of hydrocortisone produced a graded improvement in the response to a water load. It is also apparent in Figs. 2 and 3 that submaximal doses of hydrocortisone converted the severe defect of three of the four group I patients to the milder defect of group II, i.e., the excretion of urine which was transiently hypotonic, but followed by a secondary rise in urinary osmolality. The effects of intravenous administration of $100 \mathrm{mg}$ of hydrocortisone in two group II patients, J. S. and G. R., given as the $\mathrm{U} / \mathrm{P}$ osmolal ratio was rising, are shown in Fig. 4. Approximately $30-60 \mathrm{~min}$ after administration, urine osmolality fell to levels below those previously obtained at any time during the water load and was sustained.

The response to hydrocortisone of all seven patients is summarized in Table I. In the group I patients (E. S., R. D., J. D., and M. M.) in association with the marked fall in minimal urine osmolality there occurred substantial increases in free water excretion. Accurate clearance values for $\mathrm{J}$. D. after the administration of hydrocortisone were not available because of a leak around the urinary catheter. There were no consistent changes in either osmolar or creatinine clearance. In the group II patients (J. S., G. R., and P. C.) hydrocortisone produced a marked fall in urine osmolality and a rise in free water clearance in all three and reversed the secondary rise in urinary osmolality in J. S. and G. R.

Response to ethanol. The administration of ethanol during a water diuresis to two of the patients in group I (J. D. and E. S.) while the urine was hypertonic, produced no response in either urinary osmolality or free water excretion, and the data were identical with those depicted in Fig. 1. In group II, however, the administration of ethanol produced a fall in urinary osmolality, if given at a time when the urine was hypotonic. Fig. 5 depicts this phenomenon in J. S. When the ethanol was given to J. S. after the rise in urinary osmolality had reached hypertonicity, there was no demonstrable effect (Fig. 5A). The administration of $30 \mathrm{~g}$ of ethanol twice, as urine osmolality began to rise, but was still hypotonic, produced a fall in urine osmolality, a rise in free water excretion, and prevented the development of hypertonicity (Fig. 5B). Qualitatively similar responses to ethanol occurred in the other group II patients G. R. and P. C. (Fig. 6). When administered while the urine was hypotonic, ethanol either reversed the late secondary rise toward hypertonicity (Figs. 1 and $6 \mathrm{~A}$ ) or improved both Uosm and free water excretion (Fig. 6B).

Responses of group I patients to ethanol plus hydrocortisone. The lack of response to ethanol in the group I patients might be due either to the absence of elevated levels of $\mathrm{ADH}$ or decreased sensitivity of the neurohypophysis to the inhibitory effects of ethanol. To assess these possibilities, two patients, J. D. and E. S., were pretreated with submaximal doses of hydrocortisone before the study. As shown in Fig. 7, after initial hydrocortisone doses of 20 and $10 \mathrm{mg}$, respectively, J. D. and E. S. were able to produce a dilute urine which, however, could not be sustained as previously documented in Figs. 3 and 4. While urinary osmolality was rising but was still hypotonic, the oral administration was associated with a response identical with that of the group II patients, i.e., a fall in urinary osmolality and preven- 
tion of the secondary rise to hypertonicity in both patients.

\section{Posterior hypopituitarism}

In order to study the action of hydrocortisone on $\mathrm{ADH}$-induced antidiuresis in subjects unable to reduce $\mathrm{ADH}$ secretion, three patients with diabetes insipidus receiving a water load were given a constant infusion of vasopressin, designed to achieve levels of urinary osmolality comparable with those obtained in the group I patients. Fig. 8 demonstrates the rise in U/P osmolality with vasopressin infusion. The administration of $100 \mathrm{mg}$ of hydrocortisone intravenously during the antidiuresis had no demonstrable effects. To eliminate the possibility that glucocorticoid deficiency was a prerequisite to a tubular action of hydrocortisone, the identical study was performed in a patient with combined anterior and posterior pituitary insufficiency. Fig. 9 demonstrates that in this patient, the administration of intravenous hydro-
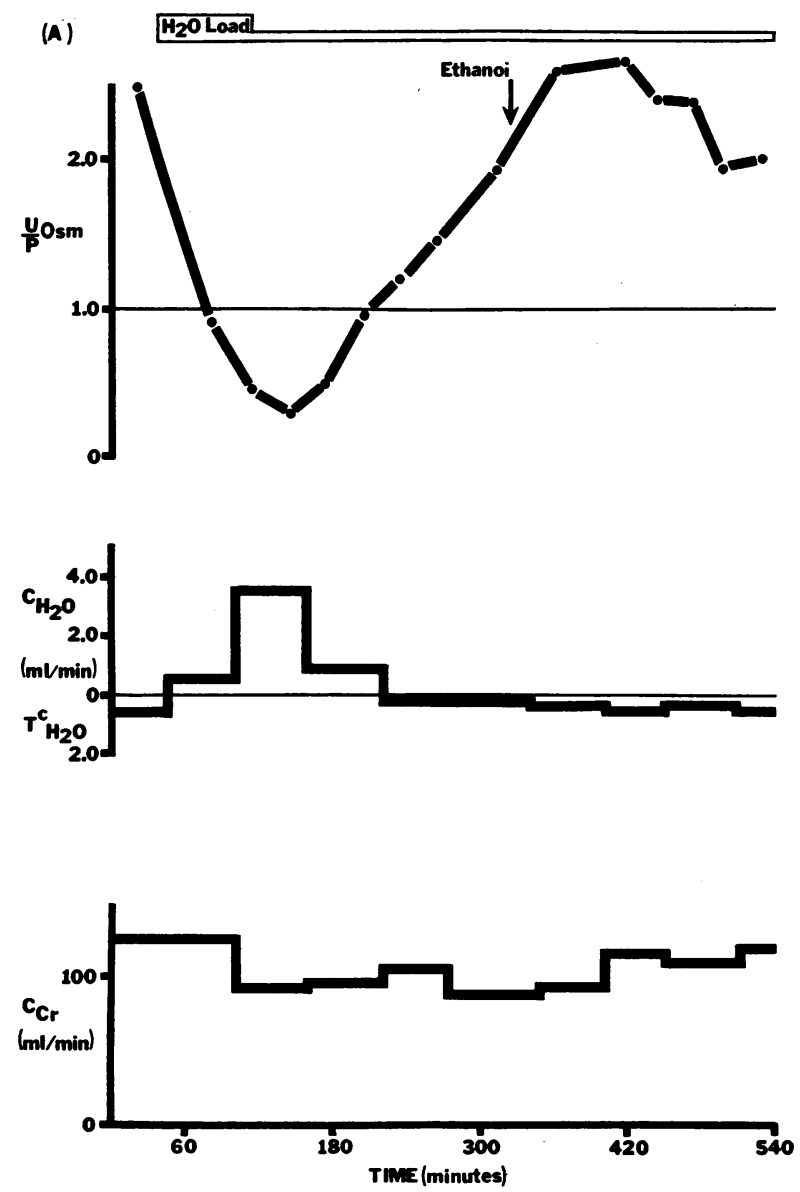

cortisone had not effect upon the vasopressin induced antidiuresis. Table II is a summary of the effect of intravenous hydrocortisone upon osmolar clearance, free water excretion, and creatinine clearance in these four patients receiving both a water load and vasopressin infusion. Free water excretion continued to fall in all with hydrocortisone administration.

\section{DISCUSSION}

Inability to excrete a water load in hypopituitarism is well documented, and hyponatremia has been recognized as a frequent manifestation (1-5). The defect has been shown to be correctable by glucocorticoid administration $(2,3,5)$, but the pathophysiologic mechanisms involved remain controversial and incompletely understood. In the present study, seven patients with anterior hypopituitarism were studied, and in all there was a defect in water excretion. The defect was quite variable, and
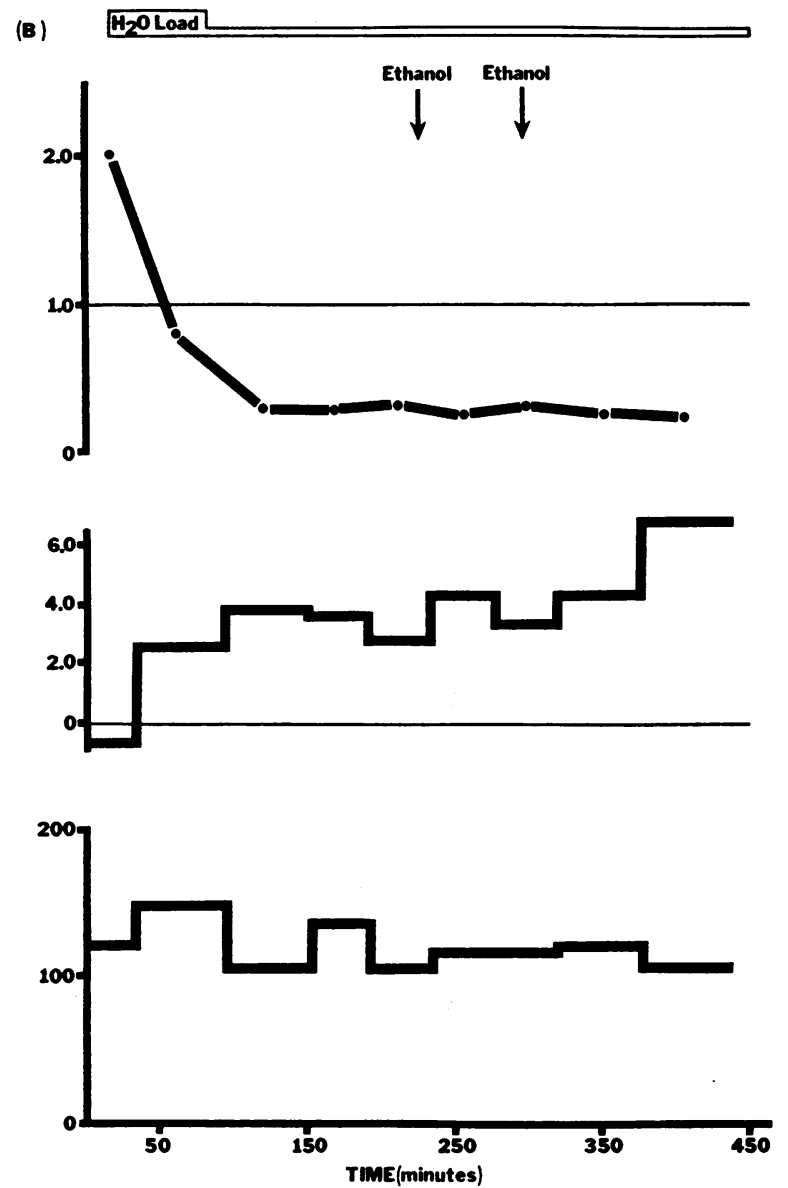

FIGURE 5 The effects of ethanol upon urinary dilution, solute-free water excretion, and creatinine clearance during a sustained water load in J. D. (A) $30 \mathrm{~g}$ ethanol administered orally when the urine was hypertonic. (B) $30 \mathrm{~g}$ ethanol administered orally twice when the urine was hypotonic. 
(A)
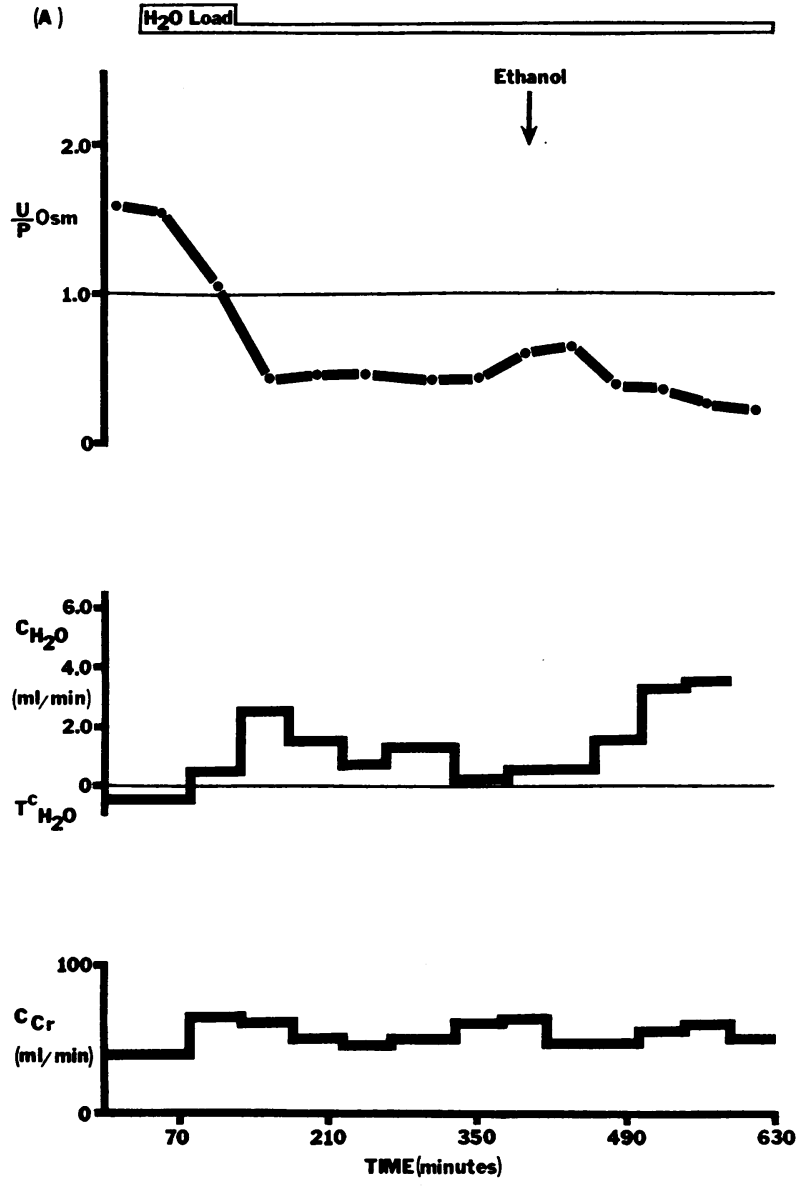

(B)

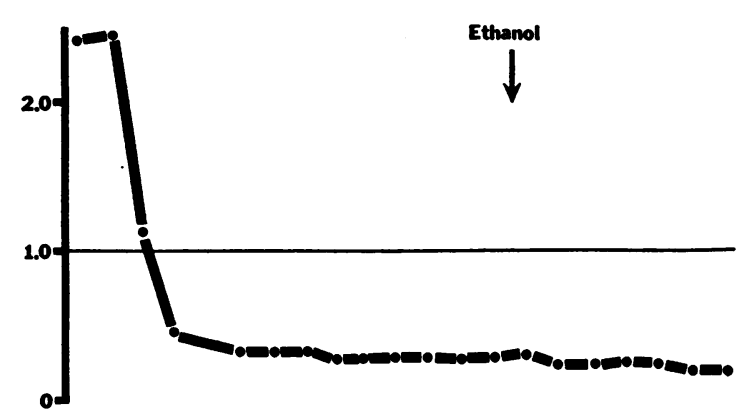

FIgURE 6 The effect of the oral administration of $30 \mathrm{~g}$ ethanol upon urinary dilution, solutefree water excretion, and creatinine clearance in patients G. R. (A) and P. C. (B). The ethanol was given at a time when the urine was hypotonic.

a spectrum of responses was found ranging from total inability to dilute the urine to an almost normal response. The patients were divided into two groups based upon their ability to respond. Four patients were unable to excrete a dilute urine while three excreted a hypotonic urine. The response to oral glucocorticoids appeared to be dose related within the physiologic range. The administration of submaximal doses to patients with the most severe defect (group I) converted their response into one characteristic of the milder defect (group II), i.e., transient dilution of the urine followed by a secondary rise to hypertonicity.

Ethyl alcohol has been previously shown to prevent the antidiuresis of dehydration and hypertonic saline administration and to have no effect upon urine flow when given at the height of water diuresis or to dogs with diabetes insipidus. On the basis of these observations, ethyl alcohol is considered to be an inhibitor of $\mathrm{ADH}$ secretion. The administration of ethanol to the patients with the most severe defect in our studies re- sulted in no significant change in diluting ability. However, when administered to those with the milder defect, ethanol effected an improvement in diluting ability as characterized by a lowering of urinary osmolality and increased excretion of solute-free water. This response was seen only when the ethanol was given at a time when the urine was still hypotonic. When patients in group I had been pretreated with submaximal doses of glucocorticoids so that they were now able to dilute transiently the urine, the administration of ethanol at a time when the urine was hypotonic, produced as in the group II patients a fall in urinary osmolality and a rise in solute-free water excretion. The lack of response to ethanol when the urine was hypertonic, i.e. at a time when $\mathrm{ADH}$ secretion was maximal, is compatible with previously published data. Thus, ethanol is able to block the antidiuretic response to hypertonic saline when given simultaneously with the initiation of saline infusion, but has no effect when superimposed upon a hypertonic saline antidiuresis (10). Our data sug- 
(A)
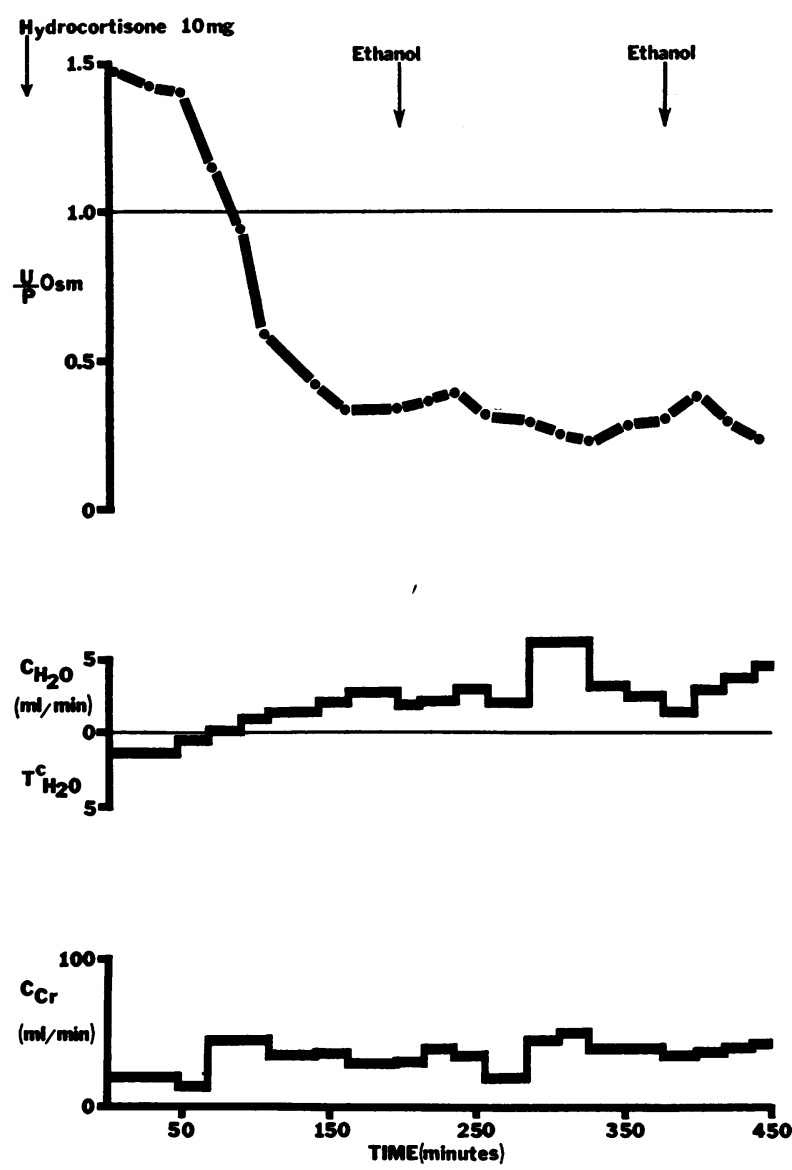

(B) HoLoad
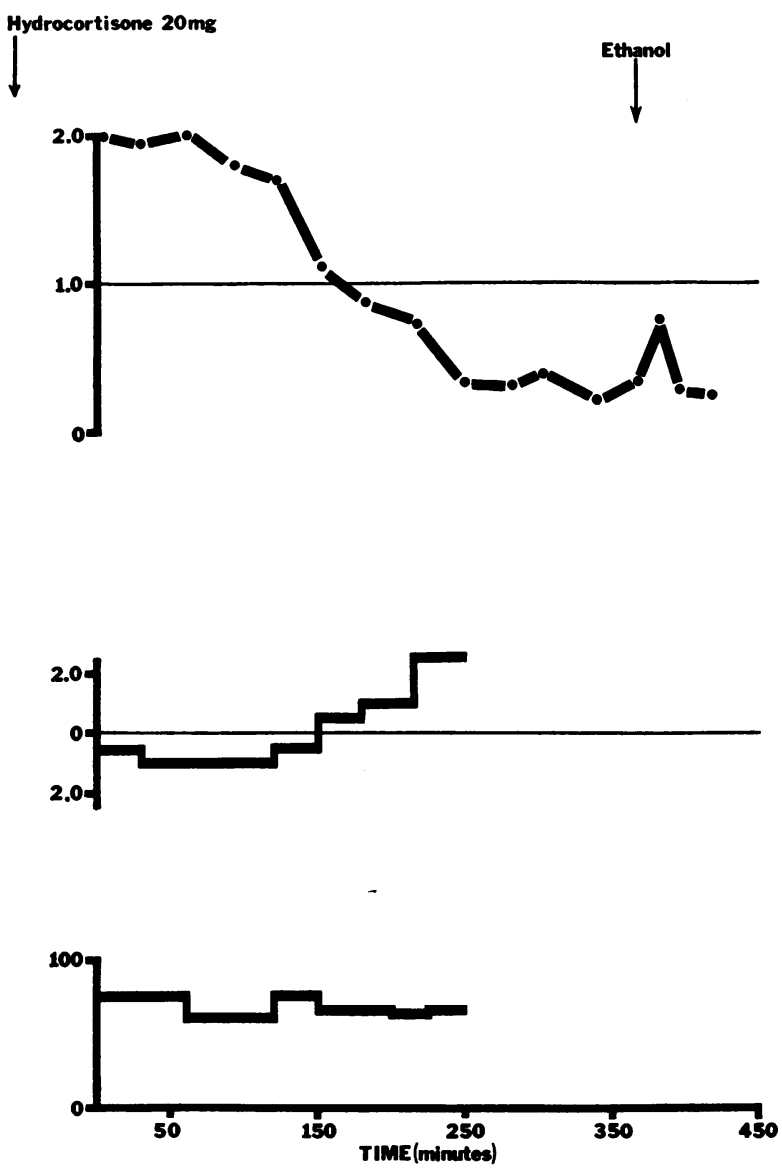

FIGURE 7 The effect of the oral administration of $30 \mathrm{~g}$ ethanol in two patients, E. S. (A) and J. D. (B), after treatment with oral hydrocortisone $1 \mathrm{hr}$ before the initiation of the sustained water load. Ethanol administration to these two patients without pretreatment with hydrocortisone had no effect upon urinary dilution (see text).

gest, therefore, that elevated levels of $\mathrm{ADH}$ play an important role in the defect in water excretion characteristic of hypopituitarism. In the most severely affected patients, the neurohypophysis responds neither to changes in plasma osmolality nor to ethanol administration while the less severely affected responded to both. The role of glucocorticoids is seen as a permissive one (5). Thus, the administration of submaximal doses of glucocorticoid, while not completely correcting the defect, permits sufficient suppression of $\mathrm{ADH}$ to allow the formation of dilute urine and a further response to ethanol.

Another possible explanation of amelioration of the defect by glucocorticoids in the presence of elevated $\mathrm{ADH}$ levels is antagonism of the peripheral action of $\mathrm{ADH}$ at the renal tubular level (6). Thus the absence of glucocorticoids would be associated with an increased sensitivity to $\mathrm{ADH}$, and glucocorticoid administration would decrease tubular permeability to water thus allowing maintenance of dilute urine and free water excretion. In order to study this possibility, patients with diabetes insipidus were given a constant infusion of vasopressin during a sustained water load. The administration of hydrocortisone intravenously had no effect upon urinary diluting ability which suggests that the beneficial action of glucocorticoids in hypopituitarism is not a direct tubular effect but rather is related to the ability to reduce circulating $\mathrm{ADH}$ levels. In order to rule out the possibility that glucocorticoid deficiency was a prerequisite for this phenomenon, an identical study was performed in a patient with both anterior and posterior pituitary insufficiency with identical results. Thus, glucocorticoids are effective in lowering urinary osmolality during a water load in the face of elevated levels of $\mathrm{ADH}$ only when the elevated levels are produced endogenously. 
The role of $\mathrm{ADH}$ in the defect in water excretion of glucocorticoid deficiency has been a source of controversy since Gaunt in 1947 first postulated a biological antagonism between $\mathrm{ADH}$ and glucocorticoids (6). Attempts to quantitate $\mathrm{ADH}$ levels directly by bioassay have yielded conflicting results, both confirming (7) and denying (8) the presence of elevated levels in this syndrome. More recently, Davis, Bloom, Field, and Mintz (16) described a patient with hypopituitarism and hyponatremia in whom urinary osmolality responded to ethanol administration when pretreated with dexamethasone similar to the patients described here. Green, Harrington, and Valtin (17) showed that they could induce a defect in the response to a water load in adrenalectomized rats with diabetes insipidus which suggests that the presence of $\mathrm{ADH}$ was not a prerequisite to the syndrome. However, when the rats were replaced with mineralocorticoids, the impairment in urinary osmolality was ameliorated even though a defect in total water excretion persisted. Thus, they could not demonstrate a defect in urinary dilution when the adrenalectomized rat with diabetes insipidus was given mineralocorticoids. As our patients with anterior hypopituitarism are able to secrete $\mathrm{ADH}$ and presumably maintained the ability to secrete mineralocorticoid (18), but still manifest a defect in urinary dilution, our conclusion that elevated levels of $\mathrm{ADH}$ are important in this syndrome are consistent with the data of Green et al. (17).

The reason for elevated levels of $\mathrm{ADH}$ in the face of hypoosmolality in patients with glucocorticoid deficiency is not clear from our data. Gill, Gann, and Bartter (19) presented data suggesting that volume repair of glucocorticoid-deficient patients led to an improvement in free water excretion, and implied that hypovolemia was the stimulus to ADH release. Share and Travis (20) demonstrated elevated ADH levels in adrenalectomized dogs and showed that this elevation could be prevented by a high salt intake. In our studies, however, the rapidity with which the defect could be corrected by intravenous glucocorticoid administration and the absence of a consistent fall in osmolar clearance after either oral or intravenous administration would argue against volume repletion as a major mechanism in the action of glucocorticoid to improve urinary-diluting ability.

In addition to elevated levels of $\mathrm{ADH}$, two other explanations have been suggested for the defect in water excretion of glucocorticoid deficiency. A decrease in delivery of glomerular filtrate to the diluting sites in the loop of Henle and distal tubules due to changes in glomerular filtration rate and/or proximal tubular reabsorptive rates could lead to a decrease in the excretion of free water and an increase in urinary osmolality (19, 21). Previous studies in the literature (22) have shown that increasing glomerular filtration rate alone in pa- tients with glucocorticoid deficiency does not correct the defect in water excretion. In our studies glucocorticoids produced an improvement in urinary dilution in
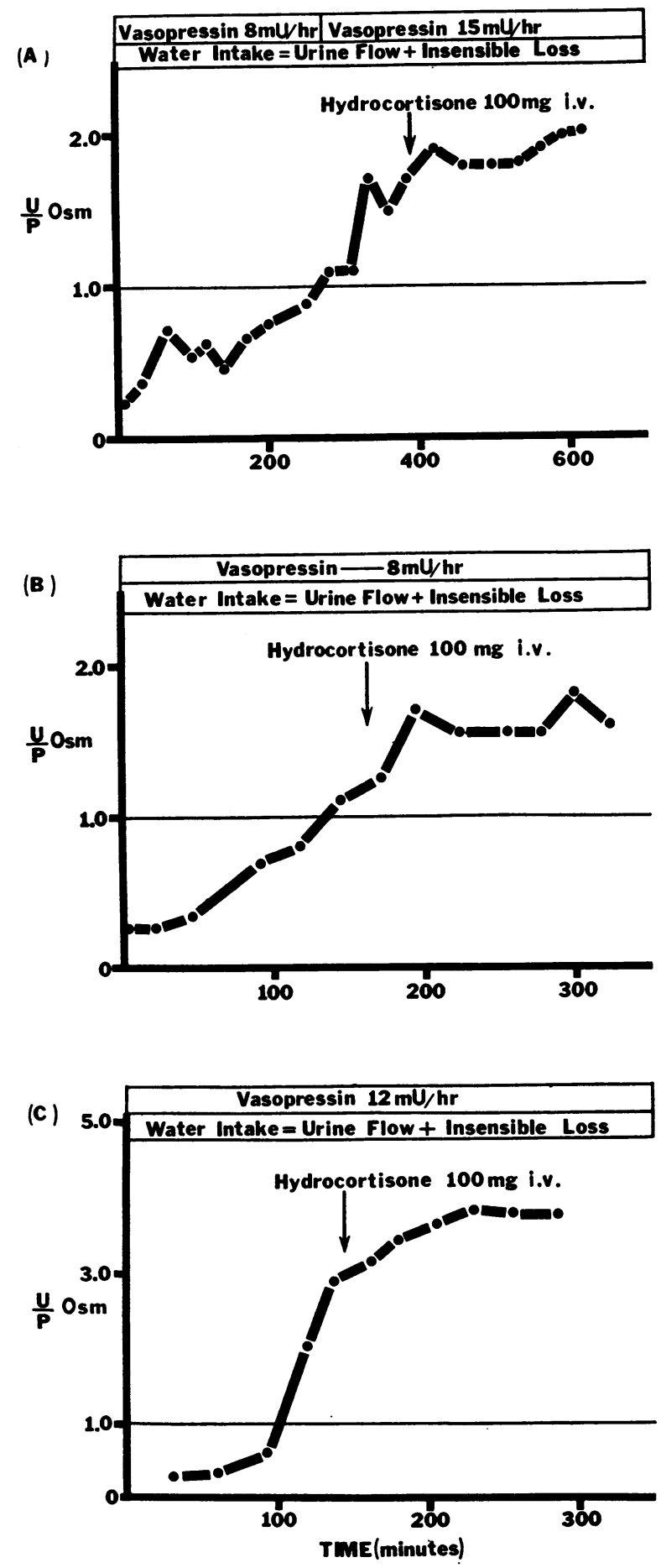

Figure 8 The effect of intravenous hydrocortisone upon urinary dilution in three patients with complete central diabetes insipidus receiving a constant infusion of vasopressin. 


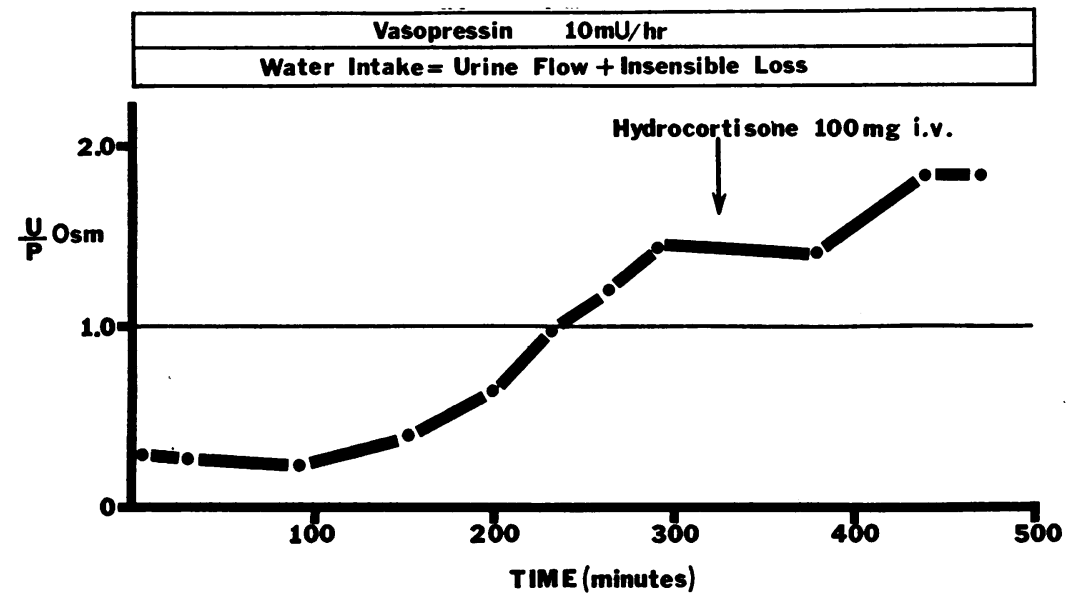

FIGURE 9 The effect of intravenous hydrocortisone upon urinary dilution in a patient with combined anterior and posterior pituitary insufficiency receiving a constant infusion of vasopressin.

all patients with anterior hypopituitarism without an associated consistent change in endogenous creatinine clearance. An increase in proximal tubular sodium reabsorption has been demonstrated in the glucocorticoiddeficient rat (23) but this has been attributed to a decreased glomerular filtration rate and perfusion pressure, and is not a direct effect of glucocorticoid deficiency. Another explanation proposed for the defect in water excretion in glucocorticoid deficiency is a change in the permeability to water of the distal tubules and collecting duct epithelium leading to increased back diffusion of water (22) in the absence of ADH. Evidence in favor of this concept is twofold. First, administration of glucocorticoids to normal man will produce an improvement in both $\mathrm{U}_{0 \mathrm{sm}}$ and $\mathrm{C}_{\mathrm{H}_{2} \mathrm{O}}$ in the absence of hemodynamic changes $(24,25)$, and secondly, glucocorticoids will restore to normal the enhanced water permeability of the distal tubule of the adrenalectomized rat (26).
Both of these observations, however, require several days of glucocorticoid therapy while the response in our studies was an immediate one. In addition, in three patients with diabetes insipidus and one with anterior pituitary insufficiency and diabetes insipidus, the intravenous administration of glucocorticoid had no effect upon either urinary osmolality or solute-free water excretion when pitressin was simultaneously infused. Thus, while changes in renal hemodynamics and distal tubular water permeability may contribute to the defect in water excretion in hypopituitarism, elevated levels of ADH secondary to glucocorticoid deficiency would appear to play a major role in this syndrome.

\section{ACKNOWLEDGMENTS}

We acknowledge the technical assistance of Mrs. Jean Elias, and are grateful to Lidia Kosolopovs and Leonid Kosolopovs for the laboratory analysis. We also wish to

TABLE II

Effects of Hydrocortisone in Patients with Diabetes Insipidus Receiving Constant Infusion of Vasopressin

\begin{tabular}{|c|c|c|c|c|c|c|c|c|}
\hline \multirow[b]{2}{*}{ Patient } & \multirow{2}{*}{$\begin{array}{c}\text { Vasopressin } \\
\text { dose }\end{array}$} & \multicolumn{3}{|c|}{ Before hydrocortisone* } & \multirow{2}{*}{$\begin{array}{l}\text { Hydro- } \\
\text { cortisone } \\
\text { dose }\end{array}$} & \multicolumn{3}{|c|}{ Posthydrocortisoneł } \\
\hline & & Cosm & $\mathrm{Cc}_{\mathrm{r}}$ & $\mathrm{C}_{\mathrm{H}_{2} \mathrm{O}}$ & & Cosm & $\mathrm{C}_{\mathrm{cr}}$ & $\mathrm{C}_{\mathrm{H}_{2} \mathrm{O}}$ \\
\hline & $m U / h r$ & & & & $m g$ & & & \\
\hline A. B. & 8 & 0.67 & 70.1 & 0.12 & 100 & 1.09 & 152 & -0.42 \\
\hline T. H. & 10 & 2.53 & 86.1 & -1.72 & 100 & 2.7 & 87.1 & -1.98 \\
\hline G. M. & 15 & 0.95 & 30.0 & -0.33 & 100 & 0.85 & 34.7 & -0.39 \\
\hline P. R. & 10 & 1.20 & 94.3 & -0.3 & 100 & 1.37 & 114 & -0.63 \\
\hline
\end{tabular}

Abbreviation as in Table I.

* Values represent the mean of three consecutive periods of 10-25 min duration before infusion of hydrocortisone.

$\ddagger$ Values represent the mean of three to four consecutive periods of 10-30 min duration beginning 30-45 min after infusion of hydrocortisone. 
thank Miss Cordelia Shute and the nursing staff of the Clinical Research Center, Hospital of the University of Pennsylvania for their cooperation.

This project was supported in part by U. S. Public Health Service grants HE-00340, HE-07284, Clinical Research Center Grant 5M01 RR40-10, Training grant AM 05634, and a Research Career Development Award AM 18,582 .

\section{REFERENCES}

1. Slessor, A. 1951. Studies concerning the mechanism of water retention in Addison's disease and in hypopituitarism. J. Clin. Endocrinol. Metab. 11: 700.

2. Oleesky, S., and S. W. Stanbury. 1956. Effect of oral cortisone on water diuresis in Addison's disease and hypopuituitarism. Lancet. 2 : 664 .

3. Garrod, O., and R. A. Burston. 1952. The diuretic response to ingested water in Addison's disease and panhypopituitarism and the effect of cortisone thereon. Clin. Sci. (London). 11: 113.

4. Bethune, J. E., and D. H. Nelson. 1965. Hyponatremia in hypopituitarism. N. Engl. J. Med. 272: 771.

5. Dingman, J. F., and R. Despointes. 1960. Adrenal steroid inhibition of vasopressin release from the neurohypophysis of normal subjects and patients with Addison's disease. J. Clin. Invest. 39: 1851.

6. Gaunt, R., J. H. Birnie, and W. J. Eversole. 1949. Adrenal cortex and water metabolism. Physiol. Rev. 29: 281 .

7. Abdul, B., J. Ahmed, B. C. George, C. Gonzalez-Auvert, and J. F. Dingman. 1967. Increased plasma arginine vasopressin in clinical adrenocortical insufficiency and its inhibition by glucosteroids. J. Clin. Invest. 46: 111

8. Kleeman, C. R., J. W. Czaczkes, and R. Cutler. 1964. Mechanisms of impaired water excretion in adrenal and pituitary insufficiency. IV. Antidiuretic hormone in primary and secondary adrenal insufficiency. J. Clin. Invest. 43: 1641 .

9. Vorherr, H., C. R. Kleeman, and M. Hoghoughi. 1968. Factors influencing the sensitivity of rats under ethanol anesthesia to antidiuretic hormone (ADH). Endocrinology. $82: 218$.

10. Kleeman, C. R., M. E. Rubini, E. Lamdin, and F. H. Epstein. 1955. Studies on alcohol diuresis II. The evaluation of ethyl alcohol as an inhibitor of the neurohypophysis. J. Clin. Invest. 34: 448.

11. Van Dyke, H. B., and R. G. Ames. 1951. Alcohol diuresis. Acta Endocrinol. $7: 110$.

12. Eggleton, M. G. 1943. The diuretic action of alcohol in man. J. Physiol. (London). 101: 172.

13. Goldberg, M. 1962. Studies of the acute renal effects of hemolyzed red blood cells in dogs, including estima- tions of renal blood flow with krypton ${ }^{85}$. J. Clin. Invest. 41: 2112 .

14. Conway, E. J. 1957. Microdiffusion Analysis and Volumetric Error. Crosby Lockwood \& Son Ltd., London. 4th edition. 248-251.

15. Goldberg, M., D. K. McCurdy, E. L. Foltz, and L. W. Bluemle, Jr. 1964. Effects of ethacrynic acid (a new saluretic agent) on renal diluting and concentrating mechanisms: evidence for site of action in the loop of Henle. J. Clin. Invest. 43: 201.

16. Davis, B. B., M. E. Bloom, J. B. Field, and D. H. Mintz. 1969. Hyponatremia in pituitary insufficiency. Metab. (Clin. Exp.). 18: 821.

17. Green, H. H., A. R. Harrington, and H. Valtin. 1970. On the role of antidiuretic hormone in the inhibition of acute water diuresis in adrenal insufficiency and the effects of Gluco- and mineralocorticoids in reversing the inhibition. J. Clin. Invest. 49: 1724.

18. Garcia, Llaurado, J. G. 1957. Aldosterone excretion following hypophysectomy in man: relation to urinary $\mathrm{Na} / \mathrm{K}$ ratio. Metab. (Clin. Exp.) 6: 556.

19. Gill, J. R., Jr., D. S. Gann, and F. C. Bartter. 1962. Restoration of water diuresis in Addisonian patients by expansion of the volume of extracellular fluid. J. Clin. Invest. 41 : 1078.

20. Share, L., and R. H. Travis. 1970. Plasma vasopressin concentration in the adrenally insufficient dog. Endocrinology. 86: 196.

21. Berliner, R. W., and D. G. Davidson. 1956. Production of hypertonic urine in absence of pituitary antidiuretic hormone. J. Clin. Invest. 35: 690.

22. Kleeman, C. R., M. H. Maxwell, and R. E. Rockney. 1958. Mechanisms of impaired water excretion in adrenal and pituitary insufficiency I. The role of altered glomerular filtration rate and solute excretion. J. Clin. Invest. 37: 1799.

23. Hierholzer, K., and H. Stolte. 1969. The proximal and distal tubular action of adrenal steroids on $\mathrm{Na}$ reabsorption. Nephron. 6: 188.

24. Raisz, L. E., W. F. McNeeley, L. Saxon, and J. D. Rosenbaum. 1957. The effects of cortisone and hydrocortisone on water diuresis and renal function in man. J. Clin. Invest. 36: 767.

25. Kleeman, C. R., J. Koplowitz, M. H. Maxwell, R. Cutler, and J. T. Dowling. 1960. Mechanisms of impaired water excretion in adrenal and pituitary insufficiency II. Interrelationships of adrenal cortical steroids and antidiuretic hormone in normal subjects and in diabetes insipidus. J. Clin. Invest. 39: 1472.

26. Stolte, H., F. P. Brecht, M. Wiederholt and K. Hierholzer. 1968. Einfluss von adrenalektomie und glucocorticoiden auf die Wasserpermeabilitat corticaler nephroabschnitte der rattenniere. Pfluegers Arch. 299: 99. 